\title{
Theoretical NMR correlations based Structure Discussion
}

\author{
Jochen Junker
}

\begin{abstract}
The constitutional assignment of natural products by NMR spectroscopy is usually based on 2D NMR experiments like COSY, HSQC, and HMBC. The actual difficulty of the structure elucidation problem depends more on the type of the investigated molecule than on its size. The moment HMBC data is involved in the process or a large number of heteroatoms is present, a possibility of multiple solutions fitting the same data set exists. A structure elucidation software can be used to find such alternative constitutional assignments and help in the discussion in order to find the correct solution. But this is rarely done. This article describes the use of theoretical NMR correlation data in the structure elucidation process with WEBCOCON, not for the initial constitutional assignments, but to define how well a suggested molecule could have been described by NMR correlation data. The results of this analysis can be used to decide on further steps needed to assure the correctness of the structural assignment. As first step the analysis of the deviation of carbon chemical shifts is performed, comparing chemical shifts predicted for each possible solution with the experimental data. The application of this technique to three well known compounds is shown. Using NMR correlation data alone for the description of the constitutions is not always enough, even when including ${ }^{13} \mathrm{C}$ chemical shift prediction.
\end{abstract}

\section{Findings}

Nuclear Magnetic Resonance allied with Elemental analysis or high resolution Mass Spectroscopy are the most common tools used for the structure elucidation of new compounds. The used 2D NMR experiments like COSY, HSQC, and ${ }^{13} \mathrm{C}-\mathrm{HMBC}$ deliver correlation information between atoms that can be translated into connectivity information. Out of these, correlation information from COSY and HSQC experiments can be transcribed directly into connectivity between atoms. But the ${ }^{13} \mathrm{C}$ HMBC correlations need more attention because of their ambiguity and complexity. Hence the difficulty of the structure elucidation problem depends more on the type of the investigated molecule than on its size [1]. Saturated compounds can usually be assigned unambiguously using mainly COSY and some ${ }^{13} \mathrm{C}-\mathrm{HMBC}$ data, whereas condensed heterocycles are problematic due to their lack of protons that could show interatomic connectivities. This ambiguity has driven the development of different software packages to aid in the interpretation of the ${ }^{13} \mathrm{C}-\mathrm{HMBC}$ correlation data [2-20] as

Correspondence: junker@cdts.fiocruz.br

Fundaçã Oswaldo Cruz - CDTS, Rio de Janeiro - RJ, Brazil much as the development of additional correlation experiments [21,22].

Most of these approaches have in common that they work only based on experimental NMR correlation data. COCON $[1,4,23,24]$ has recently been extended with the capability to create a theoretical NMR correlation data set, based on a molecule's suggested constitution. The theoretical data set is used as input data for the structure elucidation software COCON. The resulting set of constitutional assignments indicates how unambiguous NMR would have been able to describe the originally suggested molecule. The freely accessible online version of COCON (WEBCOCON at http://cocon.nmr.de) offers this analysis as "Alternative Constitutions".

The data derived from the NMR correlation spectra is the result of magnetization transfer via scalar coupling between the atoms in the molecule of interest. Since the scalar coupling is based on the interatomic bonds, the correlation data will reflect those bonds. Hence, a set of all feasible NMR correlation data (theoretical correlation data) can be derived from the molecular constitution. This is done by iteratively looking for all protons in the molecule, then building a list of their atoms in 2-bond and 3-bond distance. From each proton all 
connectivities are inspected recursively up to three bonds distance. If a carbon is found in a two bond distance, $\mathrm{a}^{2} J$ and a 1,1-ADEQUATE correlation are added to the list. If a carbon is found in a three bond distance, a HMBC correlation is added to the list, if a proton is found, a COSY correlation is added. In principle ${ }^{4} J$ correlations for COSY and $\mathrm{HMBC}$ could be generated, as sometimes they are observable in experiments as well. But, COCON can not handle ${ }^{4} J$ COSY correlations, therefore those are left out. The generation of ${ }^{4} J$ HMBC correlations is not used, because when the HMBC correlations are allowed to be ${ }^{4} J$ in the structure generation process, the process takes much more time and many more results are produced. Finally carbon chemical shifts are generated by table lookup, a table reverse generated based on the chemical shift rules that COCON uses. This values are not comparable to a chemical shift prediction, but enough to ensure that COCON will generate the starting structure.

For online use, the MarvinSketch applet from ChemAxon is available for drawing or loading of the molecule. The resulting MDL file contains all atoms, their connectivity and multiplicity information. Based on this file, the recently developed Module "Alternative Constitutions" in WEBCOCON generates atomtypes, theoretical correlation data and table-based carbon chemical shifts.

The actual magnitude of the scalar coupling, and therefore the observability of a correlation, depends on the atoms involved, their chemical environment and relative geometry. For ${ }^{1} J$ and ${ }^{2} J$ couplings mainly the atoms involved and their chemical environment are of importance, since the geometry varies little. That is different with ${ }^{3} J$ coupling, which depends on the dihedral angle, hence the actual molecular conformation decides on the magnitude of the coupling. The creation of theoretical correlation data disregards the molecule's real conformation, assuming that all correlations are observable. Hence the data set represents the upper limit of correlations that may be experimentally available for the constitution.

Calculations were run with three molecules (Figure 1) on the publicly available WEBCOCON server, running times varied from one to twelve minutes. All molecules were drawn in the "Alternative Constitutions" module and submitted to the server. The number of solutions suggested for Ascomycin 1 and Oroidin 2 in runs with theoretical and experimental data are shown in table 1. Also, a webpage allowing direct access to the results shown here has been set up on the WEBCOCON server at http://cocon.nmr.de/StructureDiscussion/ (The results are mirrored at http://science.jotjot.net/StructureDiscussion/).

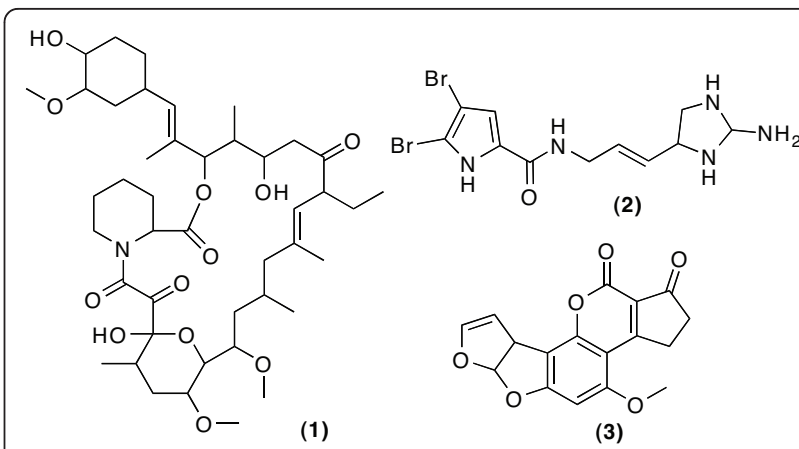

Figure 1 Ascomycin 1, Oroidin 2 and Aflatoxin B1 3 are used to evaluate the use of theoretical data.

Ascomycin $\mathbf{1}$ is a well known ethyl derivative of Tacrolimus, it serves as example of a large natural product, featuring 43 Carbon atoms. Using theoretical NMR correlation data (COSY and ${ }^{13} \mathrm{C}-\mathrm{HMBC}$ correlations) COCON generates only one solution, independent of whether atom types are defined or not. Using experimental COSY and ${ }^{13} \mathrm{C}$-HMBC correlation data the structure generator comes up with 100 structural assignments, which are reduced to one when the atom types are fixed as well. In this case NMR correlation data was able to define the constitution unambiguously.

Oroidin 2 has been frequently used for the demonstration of COCON. The use of theoretical COSY and ${ }^{13} \mathrm{C}-\mathrm{HMBC}$ correlations leads to a total of 16 possible constitutional assignments, also predefining the atom types reduces this set to one constitutional assignment. The experimental data set leads to 252,566 structural assignments generated, which reduce to 1,486 when atom types are predefined as well. Hence the structure can not be safely determined by NMR alone. The original structure determination was carried out by chemical derivatization and total synthesis [25,26].

The pictures change with Aflatoxin B1 3 with 17 Carbon atoms. Using theoretical COSY and ${ }^{13} \mathrm{C}-\mathrm{HMBC}$ data alone, COCON generates 1,048 structures, compared to 1,932 solutions using experimental data. When the atom types are predefined, COCON generates 55 constitutional assignments, compared to 108 with experimental data. The molecule set generated contains constitutions with the element cyclobutadiene, a

Table 1 Number of constitutional assignments suggested for 1 and 2.

\begin{tabular}{rrrrr}
\hline & \multicolumn{2}{c}{ open atom types } & \multicolumn{2}{c}{ fixed atom types } \\
\cline { 2 - 5 } & theo & exp & theo & exp \\
\hline 1 & 1 & 100 & 1 & 1 \\
2 & 16 & 252.566 & 1 & 1486 \\
\hline
\end{tabular}


structural element that is very uncommon in natural products. COCON has several built-in rules that eliminate certain constitutional elements, like cyclobutadiene, cyclopropene and peroxides. By default these rules are not used, but in this special case we observed a substantial difference in the number of results.

When these rules are activated the number of solutions drops to 58 for the experimental correlation data set and 33 for the theoretical data set. All planar molecules suggested are shown in Figure 2, the correct constitution and starting point of the analysis is $\mathbf{6}$. For the small number of interesting constitutions a back-calculation on the carbon chemical shifts was made (ChemDraw v11), that were compared to the experimental values (see table 2). The last line in the table contains the sum of the absolute chemical shift differences for all carbons, exposing molecule $\mathbf{6}$ as the one that best fits the experimental data $[24,27,28]$.

The theoretical NMR correlation dataset is the upper limit of number of correlations that are possible with a given constitution. Therefore all alternative constitutions generated with this data are "NMRidentical" with regard to correlation data. A careful analysis of this alternatives might be used to direct further investigations needed to confirm the proposed constitution. Whilst Ascomycin's structure can be confirmed by NMR correlations, Oroidin's structure can not. The results obtained would direct further work towards chemical derivatization and synthesis $[25,26]$ or $\mathrm{x}$-ray crystallography. The results obtained for Aflatoxin B1 show nicely how carbon chemical
Table 2 Experimental and predicted ${ }^{13} \mathrm{C}$ chemical shifts for the different constitutions suggested for Aflatoxin B1.

\begin{tabular}{lrrrrrrrr}
\hline \multicolumn{7}{c}{${ }^{13} \mathbf{C}$ shifts for molecule } \\
& exp & $\mathbf{4}$ & $\mathbf{5}$ & $\mathbf{6}$ & $\mathbf{7}$ & $\mathbf{8}$ & $\mathbf{9}$ & $\mathbf{1 0}$ \\
\hline $\mathrm{C}$ & 201 & 170 & 167 & 200 & 203 & 202 & 190 & 190 \\
$\mathrm{C}$ & 177 & 167 & 166 & 177 & 161 & 167 & 175 & 166 \\
$\mathrm{C}$ & 166 & 163 & 163 & 161 & 155 & 154 & 169 & 162 \\
$\mathrm{C}$ & 161 & 152 & 154 & 159 & 150 & 145 & 158 & 160 \\
$\mathrm{C}$ & 155 & 149 & 149 & 159 & 137 & 144 & 153 & 154 \\
$\mathrm{C}$ & 153 & 140 & 142 & 151 & 136 & 141 & 152 & 127 \\
$\mathrm{C}$ & 117 & 128 & 125 & 123 & 133 & 126 & 140 & 122 \\
$\mathrm{C}$ & 108 & 117 & 116 & 111 & 129 & 122 & 131 & 121 \\
$\mathrm{C}$ & 104 & 112 & 113 & 104 & 128 & 107 & 104 & 114 \\
$\mathrm{CH}$ & 145 & 149 & 149 & 149 & 149 & 149 & 149 & 149 \\
$\mathrm{CH}$ & 114 & 106 & 106 & 100 & 105 & 105 & 105 & 107 \\
$\mathrm{CH}$ & 103 & 105 & 105 & 100 & 100 & 94 & 93 & 101 \\
$\mathrm{CH}$ & 91 & 93 & 93 & 97 & 100 & 88 & 93 & 100 \\
$\mathrm{CH}$ & 48 & 43 & 46 & 45 & 48 & 50 & 43 & 45 \\
$\mathrm{CH}$ & 35 & 35 & 35 & 34 & 30 & 32 & 33 & 33 \\
$\mathrm{CH}_{2}$ & 29 & 24 & 21 & 28 & 25 & 31 & 14 & 14 \\
$\mathrm{CH}_{3}$ & 57 & 53 & 53 & 56 & 56 & 59 & 58 & 52 \\
\hline$\sum|\Delta \delta|$ & & 130 & 127 & $\mathbf{5 6}$ & 171 & 122 & 116 & 129 \\
\hline
\end{tabular}

shift prediction can be used as tool for the structure discussion, exposing one suggested constitutional assignment as best fitting.

\section{Availability}

The WEBCOCON server is freely accessible via http:// cocon.nmr.de.<smiles>COC(=O)C1=C2CCC3=C2C2=C(OC2)c2oc(=O)oc2C=C31</smiles><smiles>COC(=O)C1=C2CCC3=C2C(C2C=COC2)=C2C(=O)OC2=CC31</smiles><smiles>COc1cc2c(c3oc(=O)c4c(c13)CCC4=O)C1C=COC1O2</smiles><smiles>COc1cc2c(c3c(=O)oc4c(c13)CCC4=O)C1C=COC1O2</smiles><smiles>COC1=CC(=C2C(=O)OC3=C2CCC3=O)C2=C1OC1OC=CC21</smiles><smiles>COc1cc2c(c(=O)c3oc4c(c13)CCC4=O)C1C=COC1O2</smiles><smiles>COC(=O)c1cc2c(c3oc4c(c13)CCC4=O)C1C=COC1O2</smiles>

Figure 2 Planar constitutions suggested for Aflatoxin B1. Suggestions 4 - 6 are obtained using theoretical data, 5 - 10 using experimental data. Constitution 6 is the correct one. 


\section{Acknowledgements}

The author wishes to acknowledge Rainer Haessner and the Technische Universität München for providing the Hardware for the WEBCOCON Server.

\section{Authors' contributions}

JJ maintains the WEBCOCON software and has run all the calculations shown.

\section{Competing interests}

The author declares that they have no competing interests.

Received: 19 April 2011 Accepted: 28 July 2011 Published: 28 July 2011

\section{References}

1. Junker J, Maier W, Lindel T, Kock M: Computer-assisted constitutional assignment of large molecules: COCON analysis of ascomycin. Org Lett 1999, 1:737-740.

2. Elyashberg M, Williams A, Martin G: Computer-assisted structure verification and elucidation tools in NMR-based structure elucidation. Prog Nucl Mag Res Sp 2008, 53(1-2):1-104.

3. Peng C, Bodenhausen G, Qiu S, Fong H, Farnsworth N, Yuan S, Zheng C: Computer-assisted structure elucidation: Application of CISOC-SES to the resonance assignment and structure generation of betulinic acid. Magn Reson Chem 1998, 36(4):267-278.

4. Lindel T, Junker J, Kock M: COCON: From NMR correlation data to molecular constitutions. J Mol Model 1997, 3:364-368.

5. Stefani $R$, Nascimento $P$, Costa F: Computer-aided structure elucidation of organic compounds: Recent advances. Quim Nova 2007, 30(5):1347-1356.

6. Elyashberg M, Blinov K, Molodtsov S, Williams A, Martin G. Fuzzy structure generation: A new efficient tool for computer-aided structure elucidation (CASE). J Chem Inf Model 2007, 47(3):1053-1066.

7. Smurnyy $Y$, Elyashberg M, Blinov K, Lefebvre B, Martin G, Williams A: Computer-aided determination of relative stereochemistry and $3 D$ models of complex organic molecules from 2D NMR spectra. Tetrahedron 2005, 61(42):9980-9989.

8. Sharman G, Jones I, Parnell M, Willis M, Mahon M, Carlson D, Williams A, Elyashberg M, Blinov K, Molodtsov S: Automated structure elucidation of two unexpected products in a reaction of an alpha, beta-unsaturated pyruvate. Magn Reson Chem 2004, 42(7):567-572.

9. Steinbeck C: Recent developments in automated structure elucidation of natural products. Nat Prod Rep 2004, 21(4):512-518.

10. Schulz K, Korytko A, Munk M: Applications of a HOUDINI-based structure elucidation system. J Chem Inf Comp Sci 2003, 43(5):1447-1456.

11. Steinbeck C: SENECA: A platform-independent, distributed, and parallel system for computer-assisted structure elucidation in organic chemistry. J Chem Inf Comp Sci 2001, 41(6):1500-1507.

12. Steinbeck C: Recent advancements in the development of SENECA, a computer program for Computer Assisted Structure Elucidation based on a stochastic algorithm. Abstr Pap Am Chem S 1999, 218:U360-U360.

13. Strokov I, Lebedev K: Computer aided method for chemical structure elucidation using spectral databases and C-13 NMR correlation tables. Chem Inf Comp Sci 1999, 39(4):659-665.

14. Madison M, Schulz K, Korytko A, Munk M: SESAMI: An integrated desktop structure elucidation tool. Internet J Chem 1998, 1(34):CP1-U22.

15. Steinbeck C: LUCY - A program for structure elucidation from NMR correlation experiments. Angew Chem Int Edit 1996, 35(17):1984-1986.

16. Bangov I, Laude I, Cabrolbass D: Combinatorial Problems in the Treatment of fuzzy C-13 NMR Spectral Information in the Process of ComputerAided Structure Elucidation - Estimation of the Carbon-Atom Hybridization and Alpha-Environment States. Anal Chim Acta 1994, 298:33-52.

17. Funatsu K: Computer-Assisted Structure Elucidation for OrganicCompound. J Syn Org Chem Jpn 1993, 51(6):516-528.

18. Lebedev K, Nekhoroshev S, Kirshansky S, Derendjaev B: Computer Method of Fragmentary Formula Prediction of an unknown by its Mass and NMR-Spectra. Sibirskii Khim Zh+ 1992, 3: 72-79.

19. Guzowskaswider B, Hippe Z: Structure Elucidation of organic-compounds aided by the Computer-Program System Scannet. J Mol Struct 1992, 275:225-234

20. Nuzillard J, Massiot G: Computer-Aided Spectral Assignment in NMR Spectroscopy. Anal Chim Acta 1991, 242:37-41.
21. Reif B, Kock M, Kerssebaum R, Kang H, Fenical W, Griesinger C: ADEQUATE, a new set of experiments to determine the constitution of small molecules at natural abundance. J Magn Reson Ser A 1996, 118(2):282-285.

22. Kock M, Junker J, Lindel T: Impact of the H-1, N-15-HMBC experiment on the constitutional analysis of alkaloids. Org Lett 1999, 1:2041-2044.

23. Lindel T, Junker J, Kock M: 2D-NMR-guided constitutional analysis of organic compounds employing the computer program COCON. Eur $J$ Org Chem 1999, 573-577.

24. Kock M, Junker J, Maier W, Will M, Lindel T: A COCON analysis of protonpoor heterocycles - Application of carbon chemical shift predictions for the evaluation of structural proposals. Eur J Org Chem 1999, 579-586.

25. Garcia E, Benjamin L, Fryer R: Reinvestigation into structure of Oroidin, a bromopyrrole derivative from marine sponge. J Chem Soc Chem Comm 1973, 3: 78-79.

26. Forenza S, Minale L, Riccio R: New bromo-pyrrole derivatives from sponge Agelas-Oroides. J Chem Soc Chem Comm 1971, 18: 1129-1130.

27. Meiler J, Sanli E, Junker J, Meusinger R, Lindel T, Will M, Maier W, Kock M: Validation of structural proposals by substructure analysis and C-13 NMR chemical shift prediction. J Chem Inf Comp Sci 2002, 42:241-248.

28. Meiler J, Kock M: Novel methods of automated structure elucidation based on C-13 NMR spectroscopy. Magn Reson Chem 2004 42(12):1042-1045.

doi:10.1186/1758-2946-3-27

Cite this article as: Junker: Theoretical NMR correlations based Structure

Discussion. Journal of Cheminformatics 2011 3:27.

\section{Publish with ChemistryCentral and every scientist can read your work free of charge \\ "Open access provides opportunities to our colleagues in other parts of the globe, by allowing anyone to view the content free of charge." W. Jeffery Hurst, The Hershey Company.}

- available free of charge to the entire scientific community

- peer reviewed and published immediately upon acceptance

- cited in PubMed and archived on PubMed Central

- yours - you keep the copyright

Submit your manuscript here:

http://www.chemistrycentral.com/manuscript/<smiles>c1ccccc1</smiles>

ChemistryCentral 